\title{
Frequency of authorship in the Journal of Experimental Psychology
}

\author{
CARL P. DUNCAN \\ Northwestern University, Evanston, Illinois 60201
}

\begin{abstract}
A sample of authors of articles in the Journal of Experimental Psychology showed that $67 \%$ of the authors published only one article in that journal during the period 1950-1969. Sixteen percent of the authors produced $46 \%$ of the articles.
\end{abstract}

After having published one article in a prime data journal, how many authors publish in that journal again? Subjectively, it has seemed to me that the dropout rate is quite high. To gather some data on this issue, the Journal of Experimental Psychology (JEP) was examined over the 20-year period, 1950 through 1969. (Arthur Melton was the editor for the first 12 years of this period, David Grant for the last 8.) In 1950 there was one volume (Volume 40) in which were published 95 articles. When Grant took over from Melton, there were two volumes, containing a total of about 200 articles per year. In 1969 the journal had four volumes, totaling over 400 articles. Thus, the number of articles per year essentially doubled during Melton's 12-year tenure, for an average compound interest rate of about $6 \%$ per year. But the rate was increasing, since publications per year doubled again during the 8 years of Grant's editorship that are included in the present study, giving an average compound interest rate of about $9 \%$ per year for that period. Over the 20 years, almost 4,000 articles were published.

To study frequency of authorship, a sample was selected consisting of all articles for which the last name of the author began with "S." Included were all publications having an S-named person either the sole

Table 1

Articles Published by Authors with Surnames Beginning with " $S$ " in the Journal of Experimental Psychology, 1950-1969

\begin{tabular}{cc}
\hline Number of Authors & Number of Articles \\
\hline 137 & 1 \\
34 & 2 \\
26 & 3 \\
6 & 4 \\
3 & 5 \\
1 & 6 \\
1 & 7 \\
1 & 8 \\
2 & 9 \\
1 & 12 \\
1 & 14 \\
1 & 22 \\
\hline
\end{tabular}

author or the first author of a multi-authored article. There were 204 such authors and they published 379 articles, or about $10 \%$ of all publications. Table 1 shows the frequency distribution.

As the table shows, most who published once, $67 \%$ of this sample, did not publish again in JEP. In contrast, $33(16 \%)$ of the authors produced $174(46 \%)$ of the articles. I have some haphazard data on persons who were second, third, etc., authors that suggest the results would not be changed by including them. There is always the possibility that a person may publish in one year, then not publish again until several years later. This happened so rarely as to be negligible, at least as measured from the first decade to the second decade covered in the present study.

Of the 204 authors, 57 indicated in a footnote that the article was based on their $\mathrm{PhD}$ thesis. Of the 57, 40 had, through 1969 , published only one article in JEP. The number of theses published per year has increased over the years but the number per volume (roughly one thesis per 100 articles) has not. It is clear, however, that theses account for less than one-third of the 137 authors who published only once.

There are, of course, many reasons why an author would publish only once in the JEP. Over the years the JEP has changed in a number of ways, such as publishing fewer experiments in which animals are used as subjects. Some singe-article authors, and some of the thesis authors with only one JEP article, are now well known because they are publishing in other journals. Nevertheless, most authors who publish in the JEP do not publish there again. In sharp contrast, it may be noted that although the JEP is a prime data, not a theoretical, journal, and although it mainly publishes work on human, not animal, subjects, and although the present study covers only a portion of his publishing career, the person who was sole or first author of the 22 articles shown in Table 1 was Kenneth W. Spence.

(Received for publication April 24, 1978.) 